\title{
POLSKA SUBKULTURA OTAKU WOBEC ŹRÓDEŁ JAPOŃSKICH
}

Matgorzata RutKowSKa

Wydział Nauk Humanistycznych, Uniwersytet Kardynała Stefana Wyszyńskiego;

Faculty of Humanities Cardinal Stefan Wyszyński University in Warsaw (Poland).

malgorzata.rutkowska8@gmail.com

Otaku to termin oznaczający osobę silnie uzależnioną od wytworów japońskiej popkultury: anime i mangi, gier video, komputerów, fantastyki, filmów $\mathrm{z}$ efektami specjalnymi, figurek przedstawiających postaci $\mathrm{z}$ anime itd. ${ }^{1}$ Jednakże w takim rozumieniu zaczęto używać terminu otaku dopiero w latach 80. XX wieku. Wcześniej używano go do określenia osób zafascynowanych jakimś jednym aspektem rzeczywistości, konkretnym przedmiotem. Może to być np. grupa ludzi interesujących się pociągami albo osoby, które są zafascynowane aktorem czy piosenkarzem. Skrótowa definicja, jaką możemy odnaleźć w słowniku poświęconym w całości terminom związanym z kulturą otaku, to: „Otaku: nerd, geek or fanboy. A hardcore or cult fan” [Otaku: nerd, maniak, fan].

Sama geneza tego terminu jest dosyć zaskakująca, ponieważ w języku japońskim oznacza on zaimek „ty”. Trzeba jednak podkreślić, że, inaczej niż w języku polskim, w japońszczyźnie istnieje ponad dwadzieścia zaimków osobowych pierwszej i drugiej osoby, używanych w konkretnych sytuacjach oraz uzależnionych od wieku, statusu, płci i innych czynników. „Otaku oznacza ty niebezpośrednie, grzeczne i sugerujące dystans między

${ }^{1} \mathrm{H}$. Azuma, What is otaku culture?, thum. Jonathan E. Abel and Shion Kono, [w:] tejże, Otaku. Japan's database animals, London 2009, s. 3.

${ }^{2}$ P.W. Galbraith, The Otaku Encyklopedia, An insider's guide to the subculture of Cool Japan, Tokyo/New York/London, 2009, hasło: Otaku. 
rozmówcami"’. Używanie tej formy świadczy o braku osobistego zaangażowania w życie drugiej osoby oraz braku chęci podzielenia się z kimś własnymi doświadczeniami życiowymi. Omawiany wyraz jest stosowany zwykle przez starsze kobiety, gospodynie domowe, które spotykają się przy okazji swojego hobby, ale nie są przyjaciółkami i nie mają zamiaru zmieniać tej relacji na bardziej zażyłą. Sądzę, że używają jej również z powodów językowych, gdyż otaku dosłownie oznacza ,szanowny mój dom, własny dom” (człon $o$ sugeruje honoryfikatywność, taku 宅 to „moja przestrzeń życiowa, mój dom”, w odróżnieniu od słowa ie 家oznaczającego „dom, mieszkanie”, nieważne czy nasze własne, czy kogoś innego). Istnieje co prawda słowo 主 婦 shufu, oznaczające ,gospodynię domową”, ale jest ono używane przez osoby trzecie, same zainteresowane będą mówić na siebie właśnie otaku.

Uważa się, że młodzi maniacy popkultury japońskiej przesiadywali bardzo długo w domu, mieli problemy z utrzymywaniem kontaktów ze społeczeństwem, odcinali się wręcz od niego i dlatego też zaczęli niebezpośrednio mówić na siebie właśnie otaku (jako ten związany z domem), naśladując niejako swoje matki (określające same siebie tym terminem). Sami maniacy odpierają ten zarzut, twierdząc, że jedynie szli śladem innych fanów używających tego zwrotu, a nie swoich rodziców, jak twierdzi ogół $1^{4}$.

Od lat osiemdziesiątych, kiedy to mężczyźni i chłopcy, będący fanami mangi i anime, zaczęli o sobie powszechnie mówić otaku, ich subkultura „ujrzała światło dzienne”. Nie twierdzę, że subkultura otaku powstała w latach osiemdziesiątych. Istnieją bowiem dowody na to, że była ona obecna już wcześniej. Raczej nikt się jednak nią wtedy nie zainteresował, a sama skala zjawiska była znacznie mniejsza. Motywuje to podzia otaku na trzy generacje, którego dokonał Hiroki Azuma:

${ }^{3}$ J. Bator, Dzień Świra po japońsku, http://www.neww.org.pl/pl/news/ news/1,2411,1.html, [data dostępu: 21.01.13].

${ }^{4}$ P.W. Galbraith, The Otaku Encyklopedia, An insider's guide to the subculture of Cool Japan, Tokyo-New York-London, 2009, hasło: Otaku. 
Pierwsza generacja otaku to osoby, które urodziły się około 1960 roku i widziały Space Battleship Yamato (Uchũsenkan Yamato, Matsumoto Reiji, 1974 r.) oraz Mobile Suit Gundam (Kidō senshi Gandamu, Tomino Yoshiyuki, 1979 r.) w czasie ich młodzieńczych lat. Druga generacja zawiera osoby urodzone około 1970 roku, które interesowały się produktami dojrzałej kultury otaku wytworzonej przez poprzednią generację. Trzecia generacja składa się z urodzonych około 1980 roku. Byli oni w wieku licealnym w czasie, kiedy nastąpił boom na Neon Genesis Evangelion 5 .

Widzimy także, że otaku istnieli już w latach siedemdziesiątych. Trzeba jednakże zaznaczyć, że te trzy generacje niezbyt dobrze komunikowały się ze sobą, gdyż interesowały się trochę czym innym. Pierwsza generacja (w zasadzie także druga) wyrosła z zainteresowania science fiction i tego też szukała np. w anime, natomiast trzecia generacja zafascynowana była tajemniczością i grami komputerowymi. Ponadto w okresie, kiedy rozpoczynała swoją działalność, nastąpił rozwój Internetu, co spowodowało, że większa część fanów przeniosła się na fora internetowe, gdzie wyrażała swoje pasje przez tworzenie stron poświęconych mandze i anime, np. zamieszczając tam swoje obrazki ${ }^{6}$.

Z moich obserwacji wynika, że współcześnie możliwe jest wyodrębnienie czwartej generacji otaku, składającej się z ludzi urodzonych około 1990 roku, którzy są zafascynowani Dragonball (Doragon Bōru, Toriyama Akira) i Sailormoon (Bishōjo Senshi Sērā Moon, NaokoTakeuchi). Boom na te dwie serie dotarł także do Polski.

Omawiając genezę terminu otaku, trzeba wziąć pod uwagę przyczyny powstania tej subkultury i źródła jej pochodzenia. Kultura otaku wyrasta z przeszłości, z którą Japonia nie może się pogodzić i dlatego też dość długo uważano ją za zjawisko marginalne ${ }^{7}$. Chodzi tutaj o porażkę Japonii w II

${ }^{5} \mathrm{H}$. Azuma, What is otaku culture? The Three Generations of Otaku, op. cit., s. 6-7.

${ }^{6}$ Zob. ibidem, s. 7.

${ }^{7}$ J. Bator, Dzień Świra po japońsku, http://www.neww.org.pl/pl/news/ 
wojnie światowej. Japońscy intelektualiści, szukając źródła tej subkultury, stwierdzili, że termin otaku oznacza ,małego chłopca” i wziął się z nazwy bomby atomowej „Little Boy” (czyli „mały chłopiec”), którą Amerykanie zrzucili na Hiroszimę w 1945 roku. W mandze i anime bardzo często przewija się motyw zrzucenia bomby. Istnieje nawet cała manga poświęcona jedynie historii Hiroszimy przed zrzuceniem bomby i wydarzeniom, które miały miejsce tu po nim, czyli Hiroszima 1945, Bosonogi Gen (Hadashi-no Gen, Nakazawa Keiji). Powstało również anime na jej podstawie: Boso przez Hiroszime (Hadashi-no Gen, 1983 r.). To opowieść chłopca, który przeżył zrzucenie bomby na Hiroszimę. Opisał życie swoje i całej rodziny przed omawianą tragedią i po niej, co pośrednio pokazuje obraz tamtejszego społeczeństwa. W powieści powracają wielokrotnie wspomnienia dawnych czasów, a przeszłość jest nieustannie obecna.

W ten sposób Japończycy wciąż rozpatrują minioną wojnę, dając sygnał, że bardzo trudno im zaakceptować przeszłość. Wiedzą, że wraz z wojną skończyła się stara Japonia, a zaczęła nowa. Według Norihiro Kato, symptomem takiego niepogodzenia się z porażką w wojnie jest Godzilla, która jest częścią otaku industry (przemysłu otaku). Symbolizuje ona żołnierzy poległych w II wojnie światowej. Jest jakby przejawem treści znajdujących się w nieświadomości narodu japońskiego, które przedostały się na zewnątrz w formie zamaskowanej, zniekształconej,...w formie Godzilli. Według Norihiro Kato, trauma nadal nie została przezwyciężona, choć Godzilla z czasem ulegała coraz większej „kawaizacji”. Kawaii rozumieć można jako „słodki” lub „słodycz”, ale także „rozkoszny, dziecinny, fajniutki, milutki” czy „miluśki” - jednak żaden $z$ tych terminów nie oddaje pełnego znaczenia omawianego słowa. W tym kontekście chodziło Kato o to, że Godzilla z czasem coraz bardziej zaczyna przypominać człowieka, ,rozmienia się na drobne” w formie innych potworków, które zaczęły jej towarzyszyć w późniejszych filmach.

news/1,2411,1.html [data dostępu: 21.01.13]. 
Następnie doszłodo coraz większego pomniejszania, miniaturyzacji tej postaci, aż powstała Hello Kitty, ikona współczesnej popkultury Japonii.

Tłumacząc zjawisko „kawaizacji”, miniaturyzacji, koreański uczony O-Young Lee stwierdził, że wynika ono z japońskiej fascynacji małymi rzeczami, która ma stosunkowo długą tradycję. Już w Zapiskach spod poduszki (Makura-no Shōji Sei Shōnagon) w XI wieku znajdujemy wzmiankę o tym, że wszystkie małe rzeczy są godne zachwytu. O-Young Lee w swojej pracy, która jest analizą japońskiego społeczeństwa, Smaller is Better: Japan's Mastery of Miniature, argumentuje, że od wieków używali oni rozmaitych technik zmniejszania rzeczy. Kurczenie, ugniatanie, składanie, ekstrahowanie, wycinanie służyło czynieniu ich piękniejszymi, bardziej trwałymi, nowszymi i lepszymi. Przykładami mogą być: drzewka bonsai, wachlarze, lalki, dania w pudełkach na wynos obentō i walkman Sony. ${ }^{8}$. Norihiro Kato nie zgadza się z powyższą opinią, twierdzi bowiem, że ta teoria nie pomoże nam zrozumieć, skąd wzięła się ,japońska słodycz”, ponieważ „rozkwitająca kultura kawaii ma mniej wspólnego z kulturową tradycją niż ze specyficznym klimatem społecznym i politycznym powojennej Japonii”"

Jak widzimy, termin otaku, podobnie jak sama subkultura otaku (która jest częścią popkultury japońskiej), powstały na skutek buntu przeciwko systemowi edukacji, społecznemu podziałowi, normom narzuconym przez społeczeństwo.

Wydawałoby się, że skoro subkultura otaku w Polsce wywodzi się z Japonii, to jej przejawy i kształt powinny być takie same w obu krajach. Nic bardziej mylnego. Wynika to z faktu, że w Kraju Kwitnącej Wiśni otaku są częścią kultury, podczas gdy w Polsce są jedynie zapożyczonym

${ }^{8}$ K. Norihiro, Żegnaj Godzillo, Hello Kitty-źródła i znaczenie słodkiej japońskiej kultury kawaii (Goodbye Godzilla, Hello Kitty: The Origins and Meaning of Japanese Cuteness), [w:] „The American Interest” nr 1, t. II, wrzesień - listopad $2006 \mathrm{r}$.

${ }^{9}$ Ibidem. 
zjawiskiem, np. manga, która nieodmiennie kojarzy się z otaku, ma swoje źródła w malarstwie buddystycznym z XII wieku: chōjūgiga ${ }^{10}$ oraz w ukiyoe ${ }^{11}$ okresu Edo (1603-1868 r.). Warto zaznaczyć, że sam termin manga został wymyślony przez wybitnego malarza sztuki drzeworytniczej Katsuhikę Hokusaia $^{12}$. Słowo manga stało się tytułem pracy mistrza, w której uczy on rysunku. „Warto dodać, że dla mistrza słowo to miało inne znaczenie niż we współczesnym języku japońskim i oznaczać miało ,pośpiesznie narysowane szkice” (,szkice, które same, niepowstrzymane wypłynęły spod pędzla"13). Właśnie dzięki jego pracy Hokusai został okrzyknięty dziadkiem współczesnej mangi.

${ }^{10}$ Chōjū-jinbutsu-giga, w skrócie chōjūgiga (Karykatury postaci zwierzęcych). To ilustrowane zwoje $\mathrm{z}$ rysunkami zwierząt, gdzie zaznaczone były tak charakterystyczne dla współczesnego komiksu japońskiego kropelki potu czy linie sugerujące ruch. Historie były krótkie i komediowe.

P.W. Galbraith, The Otaku Encyklopedia, An insider's guide to the subculture of Cool Japan, Tokyo/New York/London, 2009, hasło: Manga.

${ }^{11}$ „Obrazy płynącego świata”. „Była to twórczość malarska i drzeworytnicza, charakterystyczna dla okresu Edo (1603-1868). Ukazywała życie w jego codziennych przejawach, zarzucając tematykę mistyczno-filozoficzną poruszaną przez malarzy z kręgów arystokratyczno-samurajskich. Najczęstszymi tematami ukiyoe były: miejskie i wiejskie scenki rodzajowe, korowody pątników i podróżników, krajobrazy, wątki i postacie związane z teatrem kabuki, dzielnicami rozrywki itp”. M. Taniguchi, Manga, czyli jak mistrz Hokusai rysunku nauczat, [w:] Świat z papieru i staliokruchy Japonii, red. M. Taniguchi i A. Watanuki, Warszawa 2006, s. 16.

${ }^{12}$ Katsuhika Hokusai (1760-1849) - malarz sztuki ukiyoe rodem z Edo, mistrz drzeworytu. W jego twórczości dominuje realizm, nie brak jednak i motywów fantastycznych czy mitologicznych; świetny pejzażysta. Jego działalność można podzielić na kilka okresów, $\mathrm{z}$ czego $\mathrm{w}$ czwartym zajmował się tworzeniem szkicowników do Mangi, w których nauczał rysunku. Za jego najsłynniejsze prace uważa się: Trzydzieści sześć widoków góry Fuji, Sto widoków góry Fuji, portrety pięknych kobiet, obrazy przedstawiające zapaśników sumo i aktorów kabuki oraz liczne ilustracje do powieści. Ibidem, s. 15.

${ }^{13}$ Ibidem, s. 17. 
Jednakże, pomimo swoich źródeł w tradycyjnych sztukach, nie można uznać mangi za produkt czysto japoński ${ }^{14}$. Według Chińczyków jest ona przełożeniem na rynek japoński chińskich książeczek obrazkowych Lianhuanhua (lian - powiązane, połączone, huan - ze sobą, wzajemnie, hua - obrazy). Jeden rysunek zajmował $90 \%$ powierzchni strony, a pozostałe $10 \%$ stanowił tekst. Prawdopodobnie Japończycy czerpiąc z tradycji chińskiej i dodając do tego własną tradycję kulturową, stworzyli coś nowego, będącego połączeniem tych dwóch źródeł. Tak właśnie powstała współczesna manga.

Jak wiadomo, z otaku kojarzy się także anime, które powstało na podobnej zasadzie, co manga. Różnica polega na tym, że anime zawiera zapożyczenia z amerykańskich źródeł. Przykładem może być słynny Tetsuwan Atomu znany na Zachodzie pod nazwą Astro Boy. Jej powstanie wynikło z zafascynowania autora bohaterem amerykańskiego komiksu, Supermanem. Twórca Astro Boya to Osamu Tezuka (1928-1989), który został okrzyknięty ojcem współczesnego anime, ale również i mangi. Tezuka w swoich pracach sięga do tematyki buddyjskiej.

Innym japońskim twórcą anime, który stał się popularny na Zachodzie, a który również czerpie źródła z innego kraju niż swój, jest Hayao Miyazaki. Zainteresował się on jednak nie amerykańską, a europejską twórczością, tzn. rosyjskim filmem animowanym pt. Królowa śniegu i na jego podstawie stworzył wszystkie swoje filmowe postacie kobiece. Jak więc widać, zarówno manga, jak i anime powstały z połączenia różnych wpływów światowych, które zostały ,przetrawione” w świadomości japońskiej, a następnie wypuszczone na rynek w postaci swoistej hybrydy różnych wpływów. W obecnych czasach nie można pozwolić sobie na traktowanie mangi i anime jako

${ }^{14}$ Informacje na temat Japonii na podstawie prelekcji pod tytułem $C z y$ manga i anime sa japońskie? prowadzone przez doktora Radosława Siedlińskiego. Prelekcja odbyła się w ramach „Warsaw Cosplay Taikai. Festiwal Kultury Japońskiej” w dniu 24.02.2013 r. o godzinie 14.30 w Polsko-Japońskiej Wyższej Szkole Technik Komputerowych z siedzibą na ulicy Koszykowej 86 w Warszawie. 
„produktów” pochodzenia wyłącznie japońskiego, także dlatego, że w ostatnich dekadach stały się one pełnoprawnym elementem globalnej kultury masowej. Jest to własność współtworzona przez niezliczone rzesze fanów na całym świecie. Faktem pozostaje jednak to, że manga i anime w jakimś stopniu czerpią z rodzimej tradycji kulturowej Japończyków i dlatego też otaku pozostaje częścią kultury popularnej Japonii. Pozwala nam to lepiej zrozumieć różnice, jakie powstają pomiędzy subkulturami otaku w Polsce i w Japonii. Jak już wspomniałam, w Polsce manga i anime są jedynie zapożyczonym zjawiskiem, co nie pozwala polskim otaku wtopić się ze swoimi zainteresowaniami w polską kulturę. W Japonii stało się to możliwe właśnie dzięki źródłom pochodzenia mangi, natomiast w Polsce nie ma takiego odniesienia. Skutkiem stało się powstanie subkultury otaku odmiennej od jej pierwowzoru.

Początków popkultury japońskiej w Polsce można szukać w latach osiemdziesiątych XX wieku' ${ }^{15}$. Były to głównie dobranocki takie jak Pszczółka Maja czy Muminki. Jednakże wówczas niewiele osób wiedziało coś o ich pochodzeniu. Mało kto miał świadomość, że ogląda anime, bo jeszcze wtedy ten termin nie był tak powszechnie znany jak obecnie.

$\mathrm{Na}$ początku lat dziewięćdziesiątych $\mathrm{XX}$ wieku, za pośrednictwem stacji telewizyjnej Polonia 1, zaczęło rosnąć zainteresowanie japońską popkulturą. Filmy anime, które zostały tam wyemitowane, były zapamiętywane jako coś japońskiego. Co prawda nadal brakowało wiedzy o tym, czym jest anime, ale już zaczęto uświadamiać sobie, że pochodzi z innego kraju. Podobnie działo się za sprawą drugiej stacji telewizyjnej, jaką było rtl7 (obecnie tvn7), która w swoim bloku o nazwie Odjazdowe kreskówki emitowała wyłącznie anime.

${ }^{15}$ Informacje na ten temat na podstawie prelekcji Daniela Stachury pod tytułem Popkultura Japońska w Polsce. Prelekcja odbyła się w ramach „Warsaw Cosplay Taikai. Festiwal Kultury Japońskiej” w dniu 24.02.2013 o godzinie 10.30 w Polsko-Japońskiej Wyższej Szkole Technik Komputerowych z siedzibą na ulicy Koszykowej 86 w Warszawie. 
Dzięki niej Polacy mogli obejrzeć takie kultowe serie jak Dragonball, Saint Seiya (Rycerze Zodiaku) czy Slayers (Magiczni wojownicy).

Symbolem coraz większego przepływu popkultury japońskiej do Polski było powstanie w 1996 roku pierwszego wydawnictwa mangowego Japonica Polonica Fantastica z siedzibą w Mierzynie. Pierwszą wydaną przez nie mangą, która była zarazem pierwszą oficjalnie wydaną mangą w Polsce, była pozycja Aż do Nieba (Ten-no hate made) autorstwa Riyoko Ikedy. Poświęcona ona była losom Stanisława Augusta Poniatowskiego. Sądzę, że JPF rozpoczęło swoją działalność właśnie od tej pozycji, gdyż dzieje Poniatowskiego są bliskie Polakom. Tym sposobem przybliżono formę komiksu japońskiego zawierającą treść nieobcą ludziom narodowości polskiej.

Od momentu pojawienia się w 1997 roku anime SailorMoon, które zostało wyemitowane przez stację telewizyjną Polsat, zainteresowani japońskimi animacjami zaczęli zgłębiać temat i poszerzać swoją wiedzę na temat tego, czym jest anime. Było to dosyć trudne, gdyż dostęp do informacji był ograniczony. Jednak dla ogółu społeczeństwa to nadal były „chińskie bajki”. W tym samym roku odbyła się pierwsza impreza związana tematycznie z grami, na której pojawił się pierwszy blok poświęcony wyłącznie mandze. Był to sygnał powolnego rozprzestrzeniania się zainteresowania związanego z japońską popkulturą. Rok 1997 to również czas pojawienia się na rynku pierwszego pisma, które zostało poświęcone całkowicie mandze, anime i Japonii. Nosiło nazwę „Kawaii” i stało się momentem przełomowym w świadomości Polaków, gdyż do tej pory nie było gazety podejmującej tematy związane z krajem tak egzotycznym jak Japonia. W tym samym czasie odbyły się także pierwsze konwenty mangowe w Gdyni.

W 1999 roku powstało drugie wydawnictwo mangowe Waneko z siedzibą w Warszawie. Sam fakt, że wydawnictwo na swoją siedzibę wybrało stolicę kraju, sugeruje, że zainteresowanie komiksami pochodzenia japońskiego wzrosło. Do rozwoju tego zjawiska przyczyniły się kasety VHS (Video Home System). Dzięki funkcji przegrywania filmów, mangowcy mogli wymieniać 
się swoimi ciężko zdobytymi zbiorami i robić kopie zapasowe. Tym sposobem fani zaczęli się spotykać w jednym miejscu głównie w celu obejrzenia niedostępnych w Polsce filmów. Rezultatem stało się zwiększenie liczby konwentów (od 3 w 1997 roku do 12 w 1999 roku), gdyż było to jedyne miejsce, w którym można było dokonać wymiany. Pierwsze konwenty miały stworzony nawet specjalnie do tego celu copy room, gdzie kopiowano anime. Nieistotne było, jaka jest tematyka danego serialu. Z racji bardzo małej dostępności fani przegrywali dosłownie wszystko, co im się udało znaleźć. Później, wraz z rozwojem wydawnictw mangowych oraz firm wydających anime na płytach, dokonywano selekcji. Same przedsiębiorstwa sprowadzały z Japonii jedynie popularniejsze serie, takie, które się sprzedadzą.

Od roku 2000, pośrednio dzięki serii telewizyjnej Pokemon i związanym z nią produktom (typu karty do gry, żetony, gry video) rozpoczął się boom na Japonię. Od tego momentu rynek mangowy zaczął się rozrastać, a samych ludzi zainteresowanych tematyką popkultury japońskiej zaczęło przybywać. Symbolem tego było chociażby powstanie wydawnictw zajmujących się nie tylko samą popkulturą, lecz także tradycyjną stroną kultury Japonii, jak wydawnictwo Hanami ${ }^{16}$.

Po 2005 roku dzięki rozwojowi Internetu dostęp do informacji o Japonii jest ułatwiony. Fani mangi, już bez wychodzenia z domu, mogą dowiedzieć się wszystkiego, czego pragną o ich hobby. Symbolem zwiększonej świadomości i wiedzy na temat tego, czym jest anime, jest np. wyświetlanie przez stacje telewizyjne serii anime w paśmie nazwanym Anime, a nie jak poprzednio: Kreskówki. Do świadomości ludzkiej dotarła informacja o istnieniu subkultury fanów mangi i anime zwanych otaku. Powstała ona na wzór istniejącej w Japonii grupy, która jednakże różni się znacznie od swojego

${ }^{16}$ Firma istnieje od 2005 roku, a dodatkowo od 2006 roku rozpoczęła działalność wydawniczą. Jejpublikacje dotyczą zagadnień z dziedziny kultury Kraju Kwitnącej Wiśni, jednakże największą część jej oferty stanowią komiksy japońskie. Informacje pochodzą ze strony www.hanami.pl [data dostępu: 25.03.13]. 
pierwowzoru. Jedną z przyczyn jest fakt jej powstawania. Jak to już zostało wspomniane, subkultura otaku w Polsce rodziła się powoli jako zjawisko zapożyczone, nie wynikała z jakiejś części kultury i historii Polski, tak jak to miało miejsce w przypadku Japonii. Samo zrozumienie tych treści wymaga większego wysiłku od Polaków, gdyż w anime istnieje wiele nawiązań do kultury japońskiej. W rezultacie niektóre zachowania fanów są dla reszty społeczeństwa niejasne. $Z$ racji swojej odmienności nie mogą stać się integralną częścią kultury polskiej.

$\mathrm{Na}$ zakończenie dokonam krótkiej charakterystyki samych otaku w obu krajach. Jak już zostało wcześniej wspomniane, japoński otaku to maniak czy też nerd. Jest osobą silnie uzależnioną od wytworów japońskiej popkultury z kręgu anime i mangi. Taka jednostka podporządkowuje swojej pasji wszystkie inne dziedziny życia. Jest w stanie poświęcić wszystko dla kultywowania swojego zainteresowania, które ze zwykłego hobby przerodziło się w sposób życia. Dlatego też można się spotkać z publikacjami na temat otaku, które ukazują ich jako zamkniętych w domu, interesujących się jedynie tym, co znajdą w pomieszczeniu, w którym przebywają. Japoński otaku ma swój własny, wirtualny świat, będący często źródłem problemów w nawiązywaniu kontaktów ze światem rzeczywistym. Taka osoba może nawet wydać pieniądze przeznaczone na zakup pożywienia na kupno anime czy też gry.

W rozumieniu ogólnym polski otaku to jedynie fan, osoba posiadająca unikalne hobby. Taka osoba nie oddaje się całkowicie swoim zainteresowaniom, tylko traktuje je jako coś, co można robić w wolnym czasie. Potrafi pogodzić rzeczywistość z fikcją, nie rezygnując z żadnego z tych elementów. Z przeprowadzonych badań wynika, że polski otaku zmuszony dokonać wyboru pomiędzy zakupem pożywienia a produktem z kręgu anime i mangi, wybierze jedzenie, gdyż nie jest w stanie poświęcić wszystkiego dla swojego hobby. Tym właśnie jest zainteresowanie mangą i anime dla polskiego otaku. W związku z tym, jeśli Japończyk mówi o sobie otaku, ma na myśli 
coś zupełnie innego niż nazywający siebie w ten sposób Polak. Odmienne rozumienie tego terminu powoduje także odmienne traktowanie siebie oraz inne postrzeganie takich osób przez społeczeństwo. Polski otaku nie będzie się wstydził tego, kim jest, gdyż nie widzi w sobie niczego złego. Nie zaniedbuje swoich obowiązków, nie myli świata rzeczywistego z wirtualnym. Posiada jedynie hobby, jakim jest zainteresowanie mangą i anime. Polski otaku na co dzień nie wyróżnia się niczym szczególnym. Jego strój czy sposób zachowania nie wskazują na żadne odchylenia od normy. Jedynie zaznajomiony $\mathrm{z}$ tematem wnikliwy obserwator może zauważyć przypinki z postaciami z anime znajdujące się na torbach czy plecakach, co sugerować może zainteresowanie tym tematem. Wyjątkiem jest czas, kiedy polscy otaku grupowo wybierają się środkami komunikacji miejskiej na odbywający się $\mathrm{w}$ danym dniu konwent. Wtedy niektórzy z ich przedstawicieli zapominają, że jeszcze nie dotarli na miejsce i zaczynają się zachowywać w sposób sugerujący odmienność. Standardowo jednak miejscem zmiany zachowania jest dopiero konwent. Można powiedzieć, że jest to jakby linia graniczna pomiędzy światem realnym a fikcyjnym. Wraz z opuszczeniem konwentu wszyscy wracają do realnego świata.

Japoński otaku natomiast nie będzie mówił z dumą o tym, kim jest ${ }^{17}$. Bycie otaku traktowane jest jako skrzywienie, odchylenie od normy. Kiedy przyglądamy się społeczeństwu japońskiemu, możemy z łatwością wskazać jednostki, które w jakiś sposób wyróżniają się spośród reszty ludności. Nawet ludzie nieposiadający wiedzy na temat otaku potrafią wskazać osoby, które nie pasują do reszty. Poznać je można po niechlujnym ubiorze, niezadbanym wyglądzie. Dzieje się tak, gdyż żyją one we własnym, wirtualnym świecie, więc nie interesuje ich zupełnie opinia społeczeństwa przebywającego

${ }^{17}$ Wszystkie informacje na temat japońskich otaku przytaczam na podstawie wywiadów przeprowadzonych z Japończykami przebywającymi na terenie Polski. Większość swojego życia spędzają oni w Japonii. Do Polski przyjeżdżają dwa razy do roku na urlop. 
w świecie realnym. Ponadto otaku stronią od ludzi, a ich zachowania społeczne postrzegane są jako odmienne.

Trzeba także wspomnieć o różnicy w podziale wewnętrznym polskich i japońskich otaku. Ci drudzy dzielą się raczej ze względu na zainteresowanie konkretnym typem anime i mangi. Tak więc mamy otaku $m o e^{18}, \operatorname{lolitek}^{19}$, Gundamów $^{20}, e c c h i^{21}$, hentai $^{22}$. Ponadto japońscy otaku to także otaku militariów, gier, efektów specjalnych oraz komiksów.

${ }^{18}$ Powstało od słowa moeru, co oznacza „płonąć”. Termin używany wśród otaku na określenie rozwijających się młodych kobiet. Zwykle są to postacie, które mają duże oczy, wygląd słodkiej dziewczynki, ale fizycznie są albo bardzo rozwinięte, albo całkiem niedojrzałe. Może to być także ubiór czy też akcesoria, jakie nosi konkretna dziewczyna np. kocie uszka, ogon, strój pokojówki lub kelnerki. Moé to uczucie, jakie wywołuje w otaku widok takich dziewczyn. Na moé składa się wiele czynników, ale podobno, nie będąc otaku, nie można dobrze pojąć określenia moé oraz wszystkich jego komponentów.

${ }^{19} \mathrm{Na}$ otaku lolitek mówi się Lolicon, co oznacza, że posiadają tzw. kompleks Lolity. Oznacza to zainteresowanie często o podłożu seksualnym dziewczynkami jeszcze niedojrzałymi do końca fizycznie. Łączy się trochę z określeniem moé, z tym, że loliconi przywiązują dużą wagę do tego, żeby konkretna dziewczyna miała ok. 12-13 lat, podczas gdy tym drugim wystarczy, by dziewczyna jedynie wyglądała na ten wiek.

${ }^{20}$ Gundamy to inaczej wielkie roboty. Nazwa wzięła się od serii anime pod tytułem Mobile Suit Gundam stworzonej w 1979 roku. Są to po prostu ludzie, którzy są zafascynowani głównie seriami o wielkich robotach (mechach). Oczywiście Gundamy nie są jedynymi seriami o wielkich robotach, ale jest to najpopularniejsza seria o tej tematyce.

${ }^{21}$ Ecchi znaczy erotyczny, o zabarwieniu seksualnym, ale nie jest to pornografia. Serie opatrzone terminem ecchi zawierają dużo postaci w krótkich spódniczkach, które są często podwiewane przez wiatr. Dopuszczalne jest pokazywanie ciała, bielizny, pocałunków, sytuacji dwuznacznych bez pokazywania samego aktu seksualnego. Otaku ecchi oglądają tylko takie serie oraz grają w tzw. ero-games, czyli właśnie gry, w których występuje element ecchi.

${ }^{22}$ Hentai to określenie używane do opisu japońskiej pornografii. Zostało wprowadzone do obiegu przez Amerykanów, którzy zapożyczyli z języka japońskiego to słowo, żeby odgraniczyć fabularną pornografię od animowanej. W Japonii hentai oznacza „dziwaka, zboczeńca”. Sami Japończycy na określenie tego typu animacji używają słowa seijin, co oznacza po prostu „dla dorosłego widza”. 
Terminem otaku w Polsce określa się jedynie grupę fanów zainteresowanych tematyką mangi i anime, gdyż tylko tacy otaku istnieją w tym kraju. Nie dzielą się oni ze względu na zainteresowanie konkretnym typem anime, lecz raczej ze względu na to, jak zachowują się w stosunku do swojego hobby, na skalę „szaleństwa" - jak to określił jeden z organizatorów konwentu. Polskich otaku można podzielić na trzy główne typy: Fani, Mangowcy oraz „Mangozjeby"23.

Fan to człowiek interesujący się mangą i anime, ale również posiadający inne zainteresowania. Nie wyróżnia się z tłumu, nie uczestniczy w cosplayu. Na konwent przyjeżdża po to, żeby miło spędzić czas, spotkać się ze znajomymi. Taka osoba niekoniecznie uczestniczy w atrakcjach organizowanych na konwentach. Najważniejsze dla niej jest przyjemne spędzanie czasu w gronie znajomych także interesujących się anime. Takie osoby najczęściej można spotkać pogrążone w rozmowie na korytarzach.

Drugim typem są Mangowcy, którzy interesują się wyłącznie mangą i anime i twierdzą, że jest to ich pasja na całe życie. Jest to grupa, która przyjeżdża na konwent głównie w celu uczestnictwa w jak największej ilości atrakcji. To ludzie otwarci na wszelkie dyskusje na temat różnych serii mangi i anime. Szanują wybór innych otaku i nie negują wyjątkowości ich ulubionych serii.

Trzecim typem są tzw. „Mangozjeby”. Jest to grupa „szaleńców”, którzy robią wiele szumu wokół swojej osoby. Są to ludzie, którzy przesadzają z kostiumami, np. noszą akcesoria pasujące do kilku postaci. Często mają na sobie kocie uszka i każde zdanie poprzedzają piskiem. Przytaczając słowa

Znakiem rozpoznawczym hentai są macki (tentacle) i różne inne dziwactwa, jakie tylko można sobie wyobrazić. Trzeba zaznaczyć, że nie każdy otaku ogląda hentai.

${ }^{23}$ Podział wewnętrzny polskich otaku stworzony na podstawie wywiadów przeprowadzonych $\mathrm{z}$ organizatorami oraz samymi uczestnikami konwentów, a także na podstawie obserwacji uczestniczącej przeprowadzonej podczas trwania konwentu. 
jednego z uczestników: „myślą, że są fajniejsi niż sama Japonia”. Do tego typu zaliczają się tzw. Narutardzi oraz Yaoistki. Ci pierwsi są fanami jednego tytułu, anime Naruto. Nie dopuszczają do siebie świadomości istnienia innych anime. Każdy, kto chciałby się wdać w nimi w dyskusję na temat innych tytułów, napotka barierę, gdyż ta grupa uważa Naruto za jedyne słuszne anime. Do Narutardów należą osoby w przedziale wiekowym od 13 do 15 lat. W związku z ich zachowaniem reszta przedstawicieli subkultury otaku ochrzciła ich właśnie mianem Narutardzi w rozwinięciu Naruto retard, co oznacza ograniczony do jednej serii. Ci drudzy, a ściślej, te drugie, gdyż do grupy Yaoistek należą tylko dziewczyny, to osoby zainteresowane yaoi, czyli typem mangi skupiającej się na relacjach fizycznych męsko-męskich. Należą do niej dziewczyny w przedziale wiekowym od 13 do 16 lat. Przyciągają je obrazy męskiego ciała, których jest bardzo dużo w tym typie mangi. Jednakże wyniki badań wskazują, że nie dostrzegają one podobieństwa między prawdziwymi relacjami homoseksualnymi a tymi przedstawionymi w komiksie. Dlatego też na przejawy homoseksualizmu w realnym świecie reagują negatywnie, odrzucając je jako coś, jak same twierdzą, obrzydliwego. Jednakże ich reakcja na ten sam typ relacji pojawiającej się w mandze jest pozytywna. Są nim wręcz zafascynowane. Trzeba dodać, że do grupy yaoistek należą tylko dziewczyny, ponieważ każdy mężczyzna, który chciałby się identyfikować $\mathrm{z}$ tą grupą, zostałby natychmiast potraktowany jako homoseksualista, mimo że prawda może być zgoła inna.

Oddzielną grupę stanowią cosplayerzy. Według organizatorów konwentów są oni aroganccy, gdyż czują się lepsi od innych uczestników konwentów (badani mówili zwłaszcza o osobach uczestniczących w konkursie cosplay). Nie dopuszczają do siebie słów krytyki, uważają się wręcz za gwiazdy. Organizatorzy twierdzą, że może być to skutek coraz większej liczby konwentów oraz zmiany w ich dostępności. Kiedyś wszyscy uczestnicy konwentów traktowali się niemalże jak rodzina, ale wraz z rozpowszechnieniem 
tego typu imprez wzrosła liczba osób, które trafiały na nie tylko z powodu ich popularności.

Takie wielkie różnice pomiędzy dwoma subkulturami otaku wynikają z innej mentalności ich członków oraz różnego rozumienia przez nich samego terminu otaku. Powoduje to nie tylko odmienne traktowanie ich przez samych siebie, lecz także sprawia, że subkultury te przejawiają się na rozmaite sposoby. Ponadto brak świadomości w umysłach przedstawicieli polskiej subkultury otaku na temat formy, w jakiej istnieje japońska, skutkuje stworzeniem grupy całkowicie odmiennej od jej pierwowzoru.

Niniejszy artykuł jest fragmentem pracy magisterskiej zatytułowanej Polska subkultura otaku wobec źródet japońskich, powstałej pod kierunkiem prof. UKSW dra hab. Roberta Cieślaka. Praca jest dostępna w archiwum Uniwersytetu Kardynała Stefana Wyszyńskiego. 


\section{Polish Otaku Culture Towards Japanese Sources}

Japanese otaku is a geek or nerd, who is strongly dependent on the products of Japanese pop culture from the circle of anime and manga. Such a unit subjugates all other areas of life to this passion, which means that he or she is willing to sacrifice everything for cultivating the interest, which from an ordinary hobby turned into a way of life. Japanese otaku has their own world, a virtual one, which often causes problems with establishing contacts with the real world.

Polish otaku however is only a fan, a person who has a unique hobby. Such a person does not sacrifice everything to their hobby and only treats it as something you can do in your free time. He or she is able to reconcile reality with fiction without sacrificing any of them. Such great differences between the two subcultures of otaku are due to different mentality of their members and various understanding of the term otaku. This causes different treatment of themselves and ways in which both subcultures otaku manifest themselves. Furthermore, the lack of awareness about Japanese otaku subculture in the minds of the representatives of Polish otaku subculture results in the creation of the group completely different from its original.

Keywords: subculture, otaku, interculturalism, Japanese culture, Polish otaku subculture, Japanese otaku subculture. 


\section{Wydawnictwo Uniwersytetu Kardynała Stefana Wyszyńskiego}

Polecamy ostatnio wydane publikacje
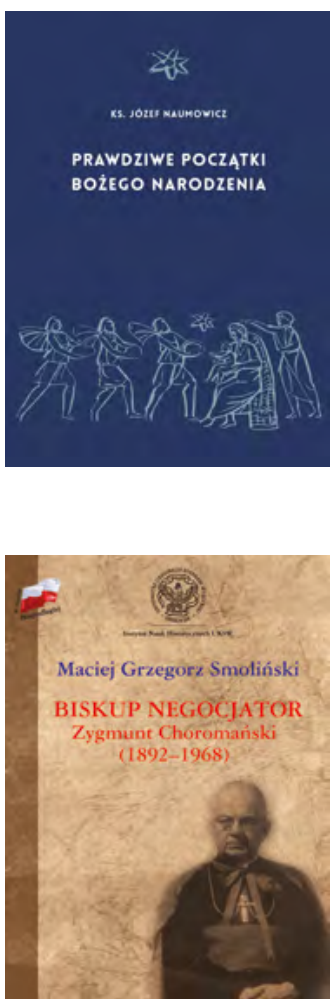

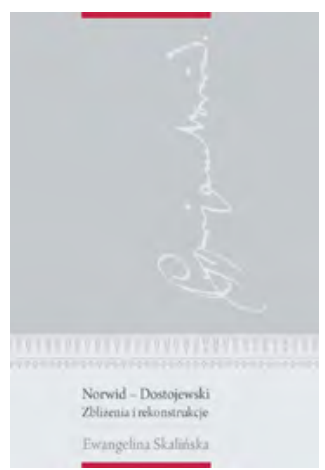

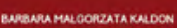

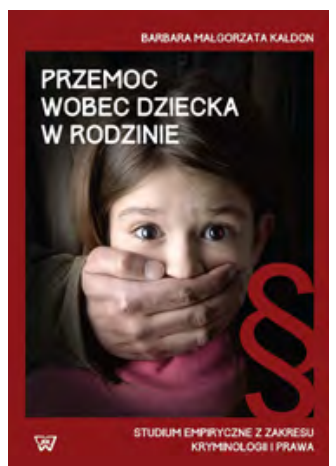

$W^{\text {ydawnictwo UKSW pu- }}$ blikuje książki naukowe i popularnonaukowe: monografie, rozprawy doktorskie i habilitacyjne, tomiki poezji, materiały pokonferencyjne, podręczniki i prace zbiorowe, o tematyce obejmującej wszystkie dziedziny, w których Uniwersytet Kardynał Stefana Wyszyńskiego prowadzi badania naukowe oraz kształcenie.

Wydawnictwo UKSW ul. Dewajtis 5, Warszawa tel. 225618838 